\title{
Long-term Clinical Outcomes and Risk of Peritoneal Seeding after Endoscopic Submucosal Dissection for Early Gastric Cancer: A Focus on Perforation during the Procedure
}

\author{
Cheal Wung Huh ${ }^{1}$, Gi Jun Kim¹, Byung-Wook Kim¹, Myeongsook Seo², and Joon Sung Kim \\ ${ }^{\prime}$ Division of Gastroenterology, Department of Internal Medicine, Incheon St. Mary's Hospital, College of Medicine, The Catholic University of \\ Korea, Seoul, and ${ }^{2}$ Department of Internal Medicine, Konkuk University Chungju Hospital, Chungju, Korea
}

\section{See editorial on page 481 .}

Background/Aims: The risk of peritoneal seeding following perforation after endoscopic resection in patients with early gastric cancer is unclear. The purpose of this study was to investigate long-term clinical outcomes including peritoneal seeding and overall survival rate following gastric perforation during endoscopic submucosal dissection (ESD). Methods: Between January 2002 and March 2015, 556 patients were diagnosed with early gastric cancer and underwent ESD. Among them, 34 patients (6.1\%) experienced gastric perforation during ESD. Clinicopathological data of these patients were reviewed to determine the clinical outcome and evidence of peritoneal seeding. Results: Among 34 patients with perforation, macroperforations occurred during ESD in 17 cases (50\%), and microperforation was identified in the remaining 17 cases (50\%). All patients except one who underwent emergency surgery due to severe panperitonitis were managed successfully by endoscopic clipping $(n=27)$ or conservative medical treatment $(n=6)$. No evidence of peritoneal seeding after perforation associated with ESD was found in our cohort. Cumulative survival rates did not differ between the perforation and non-perforation groups $(p=0.691)$. Furthermore, mortality was not associated with perforation. In addition, multivariate analysis showed that tumor size and achievement of curative resection were related to cancer recurrence. Perforation was not associated with cancer recurrence and survival. Conclusions: Perforation associated with ESD does not lead to worse clinical outcomes such as peritoneal seeding or cumulative survival rate.
Therefore, periodic follow-up might be possible if curative resection was achieved even if perforation occurred during ESD. (Gut Liver 2019;13:515-521)

Key Words: Endoscopic submucosal dissection; Perforation; Peritoneal seeding; Early gastric cancer

\section{INTRODUCTION}

Endoscopic submucosal dissection (ESD) has been recognized as a standard treatment for selected cases of early gastric cancer in Korea. ${ }^{1,2}$ Compared to surgery, ESD has advantages in that it can preserve the stomach with relatively non-invasive technique. In addition, ESD can promote high rates of en bloc resection which provides complete histologic evaluation of totally excised specimens even if lesions are massive. ${ }^{3}$ However, significant ESD-related complications including bleeding and perforation could occur., ${ }^{2,4}$

Perforation is a major complication of ESD. The incidence of ESD-related perforation has been reported to be about $1.2 \%$ to $6.1 \% .^{6-8}$ Recently, it has been reported that most perforations caused by ESD could be treated with immediate endoscopic clipping and without additional surgery. ${ }^{9}$ However, the clinical course after perforation must be taken into consideration, including peritoneal seeding. ${ }^{10,11}$ The possibility of disseminating cancer cells into the peritoneal cavity is a potential drawback associated with minimal invasive procedure such as ESD.

Whether perforation associated with endoscopic resection causes peritoneal seeding during ESD has been controversial. ${ }^{10,12}$ Therefore, the objective of this study was to investigate longterm clinical outcomes including peritoneal seeding and overall

\footnotetext{
Correspondence to: Byung-Wook Kim

Division of Gastroenterology, Department of Internal Medicine, Incheon St. Mary's Hospital, College of Medicine, The Catholic University of Korea, 56 Dongsu-ro, Bupyeong-gu, Incheon 21431, Korea

Tel: +82-32-280-5052, Fax: +82-32-280-5987, E-mail: gastro@catholic.ac.kr Received on August 8, 2018. Revised on November 28, 2018. Accepted on November 30, 2018. Published online May 27, 2019 pISSN 1976-2283 eISSN 2005-1212 https://doi.org/10.5009/gnl18350

(a) This is an Open Access article distributed under the terms of the Creative Commons Attribution Non-Commercial License (http://creativecommons.org/licenses/by-nc/4.0) which permits unrestricted non-commercial use, distribution, and reproduction in any medium, provided the original work is properly cited.
} 
survival rate following gastric perforation during ESD.

\section{MATERIALS AND METHODS}

\section{Study population}

Between January 2002 and March 2015, 556 patients who were diagnosed with early gastric cancer underwent ESD at Incheon St. Mary's Hospital, The Catholic University of Korea. Among them, 34 patients (6.1\%) experienced gastric perforation during ESD. Clinicopathological data of these 34 patients were reviewed. The Institutional Review Board of The Catholic University of Korea approved this study. The informed consent was waived due to retrospective design.

\section{ESD procedure and endoscopic clip technique}

All ESD procedures were performed by two expert endoscopists (B.W.K. and J.S.K.). After patients were moderately sedated with midazolam and propofol, ESD was performed. A video endoscope with or without a water-jet function (GIF-HQ290, GIFQ260, GIF-H260; Olympus, Tokyo, Japan) was routinely used. A disposable distal transparent cap (D-201-11804; Olympus) was mounted on the tip of the endoscope in all cases. Carbon dioxide or air was used for the insufflation. To identify target lesion, chromoendoscopy with indigo carmine solution or narrow band imaging with or without magnification was used. Following circumferential marking (using argon plasma coagulation), a mixture of indigo carmine, diluted epinephrine $(1: 200,000)$, and 10\% glycerol (Cerol; JW Pharmaceutical Co., Seoul, Korea) was used to inject submucosa as marked. Epinephrine $(1: 1,000$, total epinephrine $1 \mathrm{mg}$ ) was mixed in a 200-mL container of glycerol, and $8 \mathrm{~mL}$ of the solution was drawn into 10-mL disposable syringe to use for gastric lesion. After injection, an initial incision was made outside the marks with a dual knife or a hook knife. A knife was inserted into the initial incision, and electrosurgical current was applied with the use of an electrosurgical unit (VIO300D; Endocut I mode, effect 2; ERBE, Tubingen, Germany) to complete the circumferential mucosal incision around the lesion and submucosal dissection. The ESD procedure was performed mainly with a dual knife (KD-650Q; Olympus), an IT-knife 2 (KD-610L; Olympus), or a hook knife (KD-620LR; Olympus). Hemostatic forceps (Coagrasper, FD-410LR; Olympus) with a soft coagulation mode (VIO300D; Soft coag mode, effect 4 ; ERBE) were used to control bleeding during the procedure. In the case of macroperforation, perforation site was closed with endoclips (EZ clip; Olympus) using single closure methods. Even if there was no macroperforation, preventive clipping was performed when lesion was considered to be dissected deeply.

\section{Definition}

Perforation was classified into two types; macroperforation was defined as a gross defect noted during endoscopic procedure; microperforation was identified as a pneumoperitoneum by radiological evidence after the procedure without gross defect during the procedure. We defined curative resection according to the Japanese gastric cancer treatment guidelines as follows: en bloc resection, negative horizontal and vertical margins, no lymphovascular invasion, and one of the following: (1) tumor size $\leq 2 \mathrm{~cm}$, differentiated type, mucosa, and ulcer (-); (2) tumor size $>2 \mathrm{~cm}$, differentiated type, mucosa, and ulcer (-); (3) tumor size $\leq 3 \mathrm{~cm}$, differentiated type, mucosa, and ulcer (+); (4) tumor size $\leq 2 \mathrm{~cm}$, undifferentiated type, mucosa, and ulcer (-); or (5) tumor size $\leq 3 \mathrm{~cm}$, differentiated type, and submucosal layer 1 (SM1). ${ }^{13}$ In our study, the peritoneal seeding was defined as the direct spreading of cancer cells due to perforation during endoscopic resection.

\section{Follow-up}

After ESD, follow-up consisted of endoscopic examination at three months and biannually thereafter for 2 years followed by annual follow-up to check local or metachronous recurrence. Annual abdominal computed tomography (CT) was performed to determine extragastric recurrence. We defined "follow-up loss" as the follow-up period of less than 1 year.

\section{Statistical analysis}

Between-group comparisons of clinical characteristics were conducted using the chi-square or Fisher exact test, and applying the Student t-test for non-categorical variables. Clinicopathologic factors associated with cancer recurrence were evaluated by logistic regression analysis. The Kaplan-Meier method was used to determine cumulative survival rate and the log-rank test was used to analyze differences in survival curve. The descriptive statistics were used for continuous variables. Accepted significance level was set at $\mathrm{p}$-value $<0.05$. All statistical analyses were performed using SPSS version 20.0 for Windows (IBM Corp., Armonk, NY, USA).

\section{RESULTS}

\section{Clinicopathologic characteristics and clinical outcome between non-perforation and perforation groups}

Among 556 patients who were diagnosed with early gastric cancer and underwent ESD at Incheon St. Mary's Hospital, 17 patients were excluded due to follow-up loss. Median followup was $51.9 \pm 27.5$ months (range, 12.2 to 166.1 months). Age, sex, tumor size, macroscopic type, histology, lymphovascular invasion, curative resection, and cancer recurrence did not differ between non-perforation and perforation groups (Table 1). However, tumor location (middle and upper location) and depth of invasion (SM2 invasion) showed statistically significant associations with perforation. In perforation group, macroperforation occurred in 17 cases during ESD while microperforation occurred in the remaining 17 cases. Perforation during ESD was treated immediately by endoscopic clipping for 27 patients. One 
Table 1. Clinicopathologic Characteristics and Clinical Outcomes between the Non-perforation and Perforation Groups

\begin{tabular}{|c|c|c|c|}
\hline Characteristics & Non-perforation group $(n=505)$ & Perforation group ( $\mathrm{n}=34)$ & p-value \\
\hline Age, yr & $66.3 \pm 10.1$ & $64.3 \pm 8.2$ & 0.230 \\
\hline Sex, male:female & $358: 147$ & $27: 7$ & 0.287 \\
\hline Tumor location & & & $<0.001$ \\
\hline Upper & $29(5.7)$ & $6(17.6)$ & \\
\hline Middle & $108(21.4)$ & $19(55.9)$ & \\
\hline Lower & 368 (72.9) & $9(26.5)$ & \\
\hline Tumor size, mm & & & 0.516 \\
\hline$<20$ & $288(57.0)$ & $16(47.1)$ & \\
\hline $20-30$ & $149(29.5)$ & $12(35.3)$ & \\
\hline$>30$ & $68(13.5)$ & $6(17.6)$ & \\
\hline Macroscopic type & & & 0.405 \\
\hline Elevated & $196(38.8)$ & $17(50.0)$ & \\
\hline Flat & $143(28.3)$ & 7 (20.6) & \\
\hline Depressed & $166(32.9)$ & $10(29.4)$ & \\
\hline Histology & & & 0.481 \\
\hline Differentiated & $457(90.5)$ & $32(94.1)$ & \\
\hline Undifferentiated & $48(9.5)$ & $2(5.9)$ & \\
\hline \multicolumn{4}{|l|}{ Depth of invasion } \\
\hline Mucosa & $430(85.2)$ & 25 (73.5) & 0.010 \\
\hline SM1 $(<500 \mu \mathrm{m})$ & $42(8.3)$ & $2(5.9)$ & \\
\hline $\mathrm{SM} 2(\geq 500 \mu \mathrm{m})$ & $33(6.5)$ & $7(20.6)$ & \\
\hline Lymphovascular invasion & & & 0.350 \\
\hline Absent & 469 (92.9) & $33(97.1)$ & \\
\hline Present & $36(7.1)$ & $1(2.9)$ & \\
\hline Curative resection & & & 0.287 \\
\hline Yes & 358 (70.9) & 27 (79.4) & \\
\hline No & $147(29.1)$ & 7 (20.6) & \\
\hline Additive surgery & $50(9.9)$ & $4(11.8)$ & 0.726 \\
\hline Recurrence & $29(5.7)$ & $1(2.9)$ & 0.490 \\
\hline Local recurrence & 28 & 0 & \\
\hline Extragastric recurrence & 1 & 1 & \\
\hline Perforation & - & & - \\
\hline Macroperforation & & $17(50.0)$ & \\
\hline Microperforation & & $17(50.0)$ & \\
\hline Treatment of perforation & - & & - \\
\hline Endoscopic clipping & & $27(79.4)$ & \\
\hline Emergency surgery & & $1(2.9)$ & \\
\hline Conservative care & & $6(17.7)$ & \\
\hline
\end{tabular}

Data are presented as mean \pm SD or number $(\%)$.

SM, submucosa.

patient who suffered from panperitonitis after ESD subsequently underwent emergency surgery (wedge resection and primary repair). The remaining six patients received conservative medical treatment without endoscopic clipping or emergency surgery.

\section{Clinical outcome of patients with perforations during ESD}

Clinical outcomes of patients with macro- and micro- perforation are shown in Fig. 1. Of 34 patients, seven patients had non-curative resection while one patient had peritoneal seeding 
556 Lesions of endoscopic resection for early gastric cancer from January 2002 to March 2015

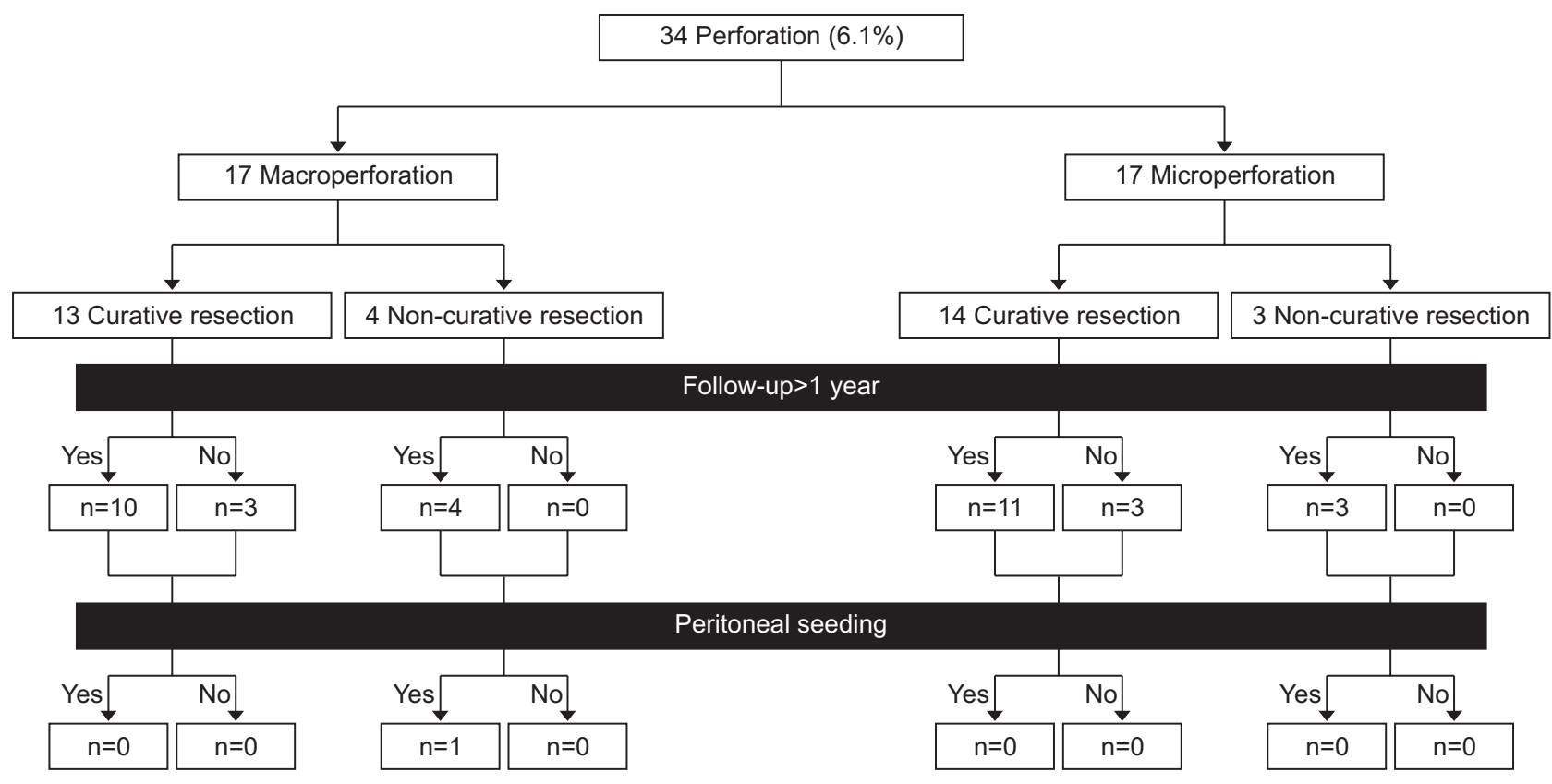

Fig. 1. Clinical outcomes of 34 patients with perforation during endoscopic submucosal dissection.

during follow-up. Table 2 shows the characteristics of these seven patients with non-curative resection. Three patients refused additional surgery while three patients underwent additional surgery (gastrectomy and lymph node dissection). One patient (patient 5) who suffered from panperitonitis after ESD subsequently underwent emergency surgery (wedge resection and simple closure without lymph node dissection). The final pathology of resected specimen revealed submucosal invasion with depth of 4,000 $\mu \mathrm{m}$. The patient was recommended to undergo additional surgery including lymph node dissection. However, the patient refused our suggestion at that time. Two years later, the patient showed massive retroperitoneal metastatic lymphadenopathy and tumor seeding with neck and brain metastasis on follow-up CT.

Univariate and multivariate analyses were performed to identify factors associated with cancer recurrence (Tables 3 and 4). Multivariate analysis showed that tumor size and achievement of curative resection were related to cancer recurrence (Table 4). Perforation was not associated with cancer recurrence.

\section{Cumulative survival rates between perforation and non- perforation groups}

We excluded patients who underwent additional surgery after non-curative resection (non-perforation group, $n=43$ and perforation group, $n=4)$. The Kaplan-Meier analysis indicated that patients with perforation had similar cumulative survival rate compared to those with non-perforation in our cohort (Fig. 2). There was no mortality associated with perforation.

\section{DISCUSSION}

The overall frequency of perforation found in our study was 6.1\% (microperforation, 50\% and macroperforation, 50\%), consistent with previous reports. ${ }^{6-8}$ Overall cumulative survival rate did not differ between perforation and non-perforation groups with median follow up of $51.9 \pm 27.5$ months. There was no evidence of peritoneal seeding after a perforation associated with ESD in this study.

Perforation is a major complication of ESD. It is related to significant morbidity and mortality. In some cases, emergency surgery is required and the risk of peritoneal seeding should be considered. ${ }^{7,9}$ Peritoneal seeding following fine needle biopsy for hepatocellular carcinoma and port-site seeding after laparoscopic surgery have been reported. ${ }^{14,15}$ Theoretically, perforation of the gastric wall in a lesion containing cancer cells during ESD may lead to peritoneal seeding.

Two studies have reported the risk of peritoneal seeding after perforation during gastric endoscopic resection to date. In a retrospective study of 90 patients with perforation after gastric endoscopic resection, there was no peritoneal seeding. ${ }^{12} \mathrm{~A}$ recent retrospective study has reported peritoneal seeding occurring in two of 22 patients with perforation following gastric endoscopic resection. ${ }^{10}$ In this previous study, the ESD specimen of one patient had pathologic vertical margin positive and deep SM invasion. Another patient with mucosal cancer underwent emergency surgery for acute peritonitis. However, several clinicopathological characteristics (e.g., curative resection, depth of invasion, type of additive operation, etc.) of these two patients 


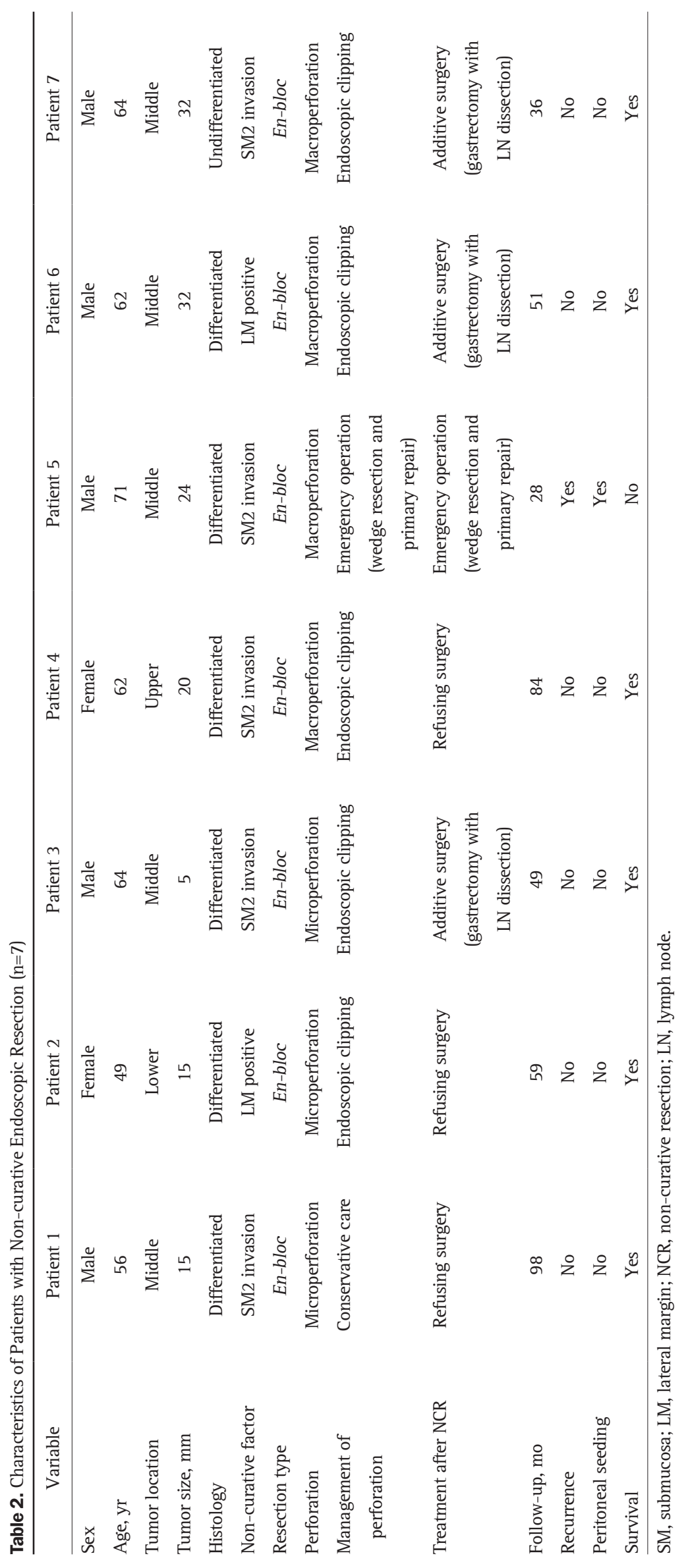


Table 3. Univariate Analysis of Clinicopathologic Characteristics Associated with Cancer Recurrence

\begin{tabular}{|c|c|c|c|}
\hline Characteristic & $\begin{array}{l}\text { No recurrence } \\
(n=509)\end{array}$ & $\begin{array}{l}\text { Recurrence } \\
(\mathrm{n}=30)\end{array}$ & p-value \\
\hline Age, yr & & & 0.143 \\
\hline$<65$ & $222(43.6)$ & $9(30.0)$ & \\
\hline$\geq 65$ & $287(56.4)$ & $21(70.0)$ & \\
\hline Sex, male:female & $363: 146$ & $22: 8$ & 0.812 \\
\hline Tumor location & & & 0.083 \\
\hline Upper & $31(6.1)$ & $4(13.3)$ & \\
\hline Middle & $124(24.4)$ & $3(10.0)$ & \\
\hline Lower & $354(69.5)$ & $23(76.7)$ & \\
\hline Tumor size, mm & & & $<0.001$ \\
\hline$<20$ & $301(59.1)$ & $3(10.0)$ & \\
\hline $20-30$ & $143(28.1)$ & $18(60.0)$ & \\
\hline$>30$ & $65(12.8)$ & $9(30.0)$ & \\
\hline Macroscopic type & & & 0.197 \\
\hline Elevated & $201(39.5)$ & $12(40.0)$ & \\
\hline Flat & $138(27.1)$ & $12(40.0)$ & \\
\hline Depressed & $170(33.4)$ & $6(20.0)$ & \\
\hline Histology & & & 0.431 \\
\hline Differentiated & $463(91.0)$ & $26(86.7)$ & \\
\hline Undifferentiated & $46(9.0)$ & $4(13.3)$ & \\
\hline \multicolumn{4}{|l|}{ Depth of invasion } \\
\hline Mucosa & $431(84.6)$ & $24(80.0)$ & 0.783 \\
\hline SM1 $(<500 \mu \mathrm{m})$ & $41(8.1)$ & $3(10.0)$ & \\
\hline $\mathrm{SM} 2(\geq 500 \mu \mathrm{m})$ & $37(7.3)$ & $3(10.0)$ & \\
\hline Lymphovascular invasion & & & 0.431 \\
\hline Absent & 473 (92.9) & 29 (96.7) & \\
\hline Present & $36(7.1)$ & $1(3.3)$ & \\
\hline Curative resection & & & $<0.001$ \\
\hline Yes & $374(73.5)$ & $11(36.7)$ & \\
\hline No & $135(26.5)$ & $19(63.3)$ & \\
\hline \multicolumn{4}{|l|}{ Perforation } \\
\hline Yes & $33(6.5)$ & $1(3.3)$ & 0.490 \\
\hline No & 476 (93.5) & 29 (96.7) & \\
\hline
\end{tabular}

Data are presented as number (\%).

SM, submucosa.

could not be verified. A case of peritoneal seeding after perforation during ESD has also been reported. ${ }^{11}$ In this case, however, cancer cell existed in muscularis propria layer in the ESD specimen. Therefore, it is unclear whether peritoneal seeding and perforation during ESD are directly linked. Furthermore, previous studies have several limitations such as relatively short-term follow-up period and lack of clinicopathological characteristics (e.g., curative resection, depth of invasion, survival rate, etc.).

To overcome such limitations, the present study was conducted with relatively long-term follow-up period. In addi-
Table 4. Multivariate Analysis of Clinicopathologic Characteristics Associated with Cancer Recurrence

\begin{tabular}{lcc}
\hline Characteristic & OR $(95 \% \mathrm{CI})$ & p-value \\
\hline Tumor size, $\mathrm{mm}$ & & \\
$<20$ & Reference & - \\
$20-30$ & $9.97(2.83-35.07)$ & $<0.001$ \\
$>30$ & $8.17(2.01-33.19)$ & 0.003 \\
Curative resection & & \\
Yes & Reference & - \\
No & $2.73(1.20-6.25)$ & 0.017 \\
\hline
\end{tabular}

OR, odds ratio; CI, confidence interval.

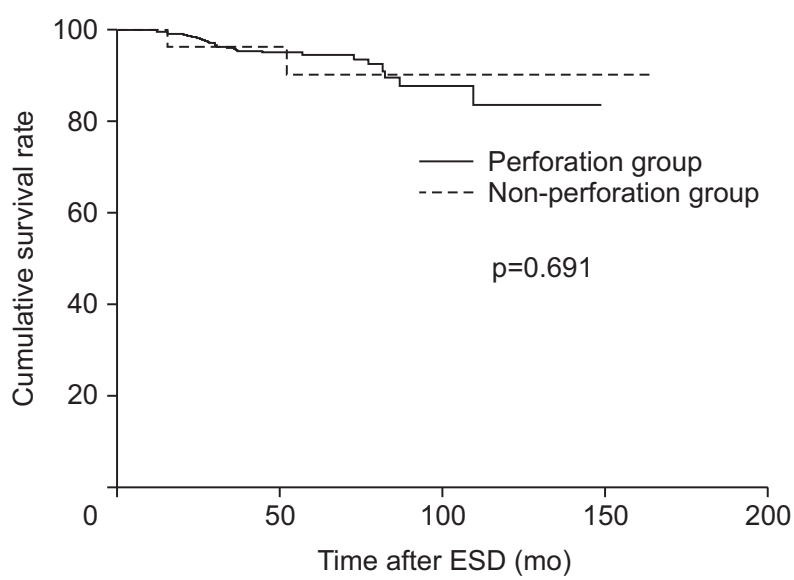

Fig. 2. Cumulative survival rates between perforation and non-perforation groups.

ESD, endoscopic submucosal dissection.

tion, several clinicopathological factors including cumulative survival rate were validated. Our results revealed that gastric perforation during ESD did not lead to peritoneal dissemination, even in the long term. Cumulative survival rates did not differ between perforation and non-perforation groups either. In the perforation group, one patient displayed massive retroperitoneal metastatic lymphadenopathy and tumor seeding with neck and brain metastasis on follow-up CT. Although peritoneal recurrence occurred in this patient, it might not be related to perforation during ESD. The patient strongly refused additional surgery including lymph node dissection. Several studies have reported that lymph node metastasis can occur in 3.4\% to 9.3\% of patients after undergoing additive surgery following noncurative resection. ${ }^{16-19}$ Thus, it is reasonable to consider the case as a multiple organ metastasis from perilesional lymph node metastasis. Although the lack of peritoneal sampling was a major limitation of the present study, this case was not peritoneal seeding due to perforation.

In our study, the perforation group and the non-perforation group showed similar cumulative survival rates even in the long term. In addition, perforation was not associated with cancer recurrence. Our results suggest that perforation associated with 
ESD procedure could be successfully managed using non-surgical method (e.g., endoscopic clipping and conservative care). In addition, if resected lesion meets "curative resection," periodic follow-up could be allowed regardless of perforation.

Our study has several limitations. First, this was a retrospective study which restricted our ability to control certain aspects of the study. Second, we did not perform peritoneal lavage in patients with perforation. Third, the number of perforations was relatively small due to low rates of perforation. Nevertheless, our study has the strength of long-term follow up for clinical courses of patients with perforation.

In conclusion, results of this study demonstrated that perforation during ESD was not accompanied by worse clinical outcome such as peritoneal seeding and cumulative survival rate. Therefore, periodic follow-up is possible if curative resection is achieved regardless of perforation during ESD.

\section{CONFLICTS OF INTEREST}

No potential conflict of interest relevant to this article was reported.

\section{AUTHOR CONTRIBUTIONS}

Conception and design of the study: B.W.K. Data analysis and interpretation: C.W.H., G.J.K., M.S. Drafting of the manuscript: C.W.H. Critical revision of the manuscript for important intellectual content: J.S.K. Approval of the final version of the manuscript: all authors.

\section{ORCID}

Byung-Wook Kim https://orcid.org/0000-0002-2290-4954

\section{REFERENCES}

1. Kato M, Nishida T, Yamamoto K, et al. Scheduled endoscopic surveillance controls secondary cancer after curative endoscopic resection for early gastric cancer: a multicentre retrospective cohort study by Osaka University ESD study group. Gut 2013;62:14251432.

2. Kim SG. Endoscopic treatment for early gastric cancer. J Gastric Cancer 2011;11:146-154.

3. Isomoto H, Shikuwa S, Yamaguchi N, et al. Endoscopic submucosal dissection for early gastric cancer: a large-scale feasibility study. Gut 2009;58:331-336.

4. Toyonaga T, Man-i M, East JE, et al. 1,635 Endoscopic submucosal dissection cases in the esophagus, stomach, and colorectum: complication rates and long-term outcomes. Surg Endosc 2013;27:1000-1008.

5. Kim M, Jeon SW, Cho KB, et al. Predictive risk factors of perfora- tion in gastric endoscopic submucosal dissection for early gastric cancer: a large, multicenter study. Surg Endosc 2013;27:13721378.

6. Mannen K, Tsunada S, Hara M, et al. Risk factors for complications of endoscopic submucosal dissection in gastric tumors: analysis of 478 lesions. J Gastroenterol 2010;45:30-36.

7. Chung IK, Lee JH, Lee SH, et al. Therapeutic outcomes in 1000 cases of endoscopic submucosal dissection for early gastric neoplasms: Korean ESD Study Group multicenter study. Gastrointest Endosc 2009;69:1228-1235.

8. Imagawa A, Okada H, Kawahara Y, et al. Endoscopic submucosal dissection for early gastric cancer: results and degrees of technical difficulty as well as success. Endoscopy 2006;38:987-990.

9. Minami S, Gotoda T, Ono H, Oda I, Hamanaka H. Complete endoscopic closure of gastric perforation induced by endoscopic resection of early gastric cancer using endoclips can prevent surgery (with video). Gastrointest Endosc 2006;63:596-601.

10. Hirao M, Yamada T, Michida T, et al. Peritoneal seeding after gastric perforation during endoscopic submucosal dissection for gastric cancer. Dig Surg 2018;35:457-460.

11. Morita A, Yabushita K, Kimura J, et al. A case of stage IB gastric cancer caused peritoneal dissemination in 1 year after perforation during endoscopic submucosal dissection. Jpn J Gastroenterol Surg 2007;40:399-404.

12. Ikehara H, Gotoda T, Ono H, Oda I, Saito D. Gastric perforation during endoscopic resection for gastric carcinoma and the risk of peritoneal dissemination. Br J Surg 2007;94:992-995.

13. Japanese Gastric Cancer Association. Japanese gastric cancer treatment guidelines 2010 (ver. 3). Gastric Cancer 2011;14:113123.

14. Durand F, Regimbeau JM, Belghiti J, et al. Assessment of the benefits and risks of percutaneous biopsy before surgical resection of hepatocellular carcinoma. J Hepatol 2001;35:254-258.

15. Cook TA, Dehn TC. Port-site metastases in patients undergoing laparoscopy for gastrointestinal malignancy. Br J Surg 1996;83:1419-1420.

16. Kawata N, Kakushima N, Takizawa K, et al. Risk factors for lymph node metastasis and long-term outcomes of patients with early gastric cancer after non-curative endoscopic submucosal dissection. Surg Endosc 2017;31:1607-1616.

17. Kim ER, Lee H, Min BH, et al. Effect of rescue surgery after noncurative endoscopic resection of early gastric cancer. Br J Surg 2015;102:1394-1401.

18. Son SY, Park JY, Ryu KW, et al. The risk factors for lymph node metastasis in early gastric cancer patients who underwent endoscopic resection: is the minimal lymph node dissection applicable? A retrospective study. Surg Endosc 2013;27:3247-3253.

19. Oda I, Gotoda T, Sasako M, et al. Treatment strategy after noncurative endoscopic resection of early gastric cancer. Br J Surg 2008;95:1495-1500. 